Check for updates

London, UK

Cite this as: BMJ 2021;375:n2398 http://dx.doi.org/10.1136/bmj.n2398 Published: 04 October 2021

\title{
Why I ... am a green GP
}

\section{GP Tamsin Ellis talks to Kathy Oxtoby about how working in a green practice not only helps the environment but also enriches patient care}

\section{Kathy Oxtoby}

Like many of us, Tamsin Ellis had thought that we were years away from a climate catastrophe and that predictions of the world's demise were extreme. "I thought we had time to deal with this," she says, "but it's happening now, and we need to act now."

In 2019, when the news was dominated by climate protests, Ellis, at the time a trainee GP, was inspired to find out more. "I soon realised that climate change had huge health implications," she says.

Around that time, the Royal College of General Practitioners (RCGP) declared a climate emergency and was developing an advisory group. Ellis joined the group and connected with other GPs who, like her, were learning about practical ways to create environmentally sustainable general practices.

She also attended workshops at the Centre for Sustainable Healthcare ${ }^{1}(\mathrm{CSH})$ and the inaugural Green Impact for Health conference in Frome where she heard how Frome Medical Practice ${ }^{2}$ had been putting its green policy into practice.

"These experiences were inspiring and opened my eyes to what green general practice could be like," says Ellis. "I saw it working and thought, "This kind of practice needs to be everywhere."”

She also met the founders of the primary care climate and sustainability network Greener Practice, ${ }^{3}$ whose work inspired her to set up a local group in London in 2020.

After qualifying last year she volunteered at the $\mathrm{CSH}$ to help design a course for primary care, and for 10 months spent one day a week on its development, gathering input from GPs across the UK. "We now have a sustainable primary care course $\mathrm{e}^{4}$ that involves everyone in the multidisciplinary team," she says. The course covers the climate emergency and its connection to health, carbon footprint "hot spots" in primary care, and how to take action.

When Ellis joined the Village Practice in Islington, London, in October 2020, she found the team was keen to get involved in environmentally sustainable ways of working. This included using the RCGP's green impact for health toolkit ${ }^{5}$ to make "quick switches and easy wins" to reduce waste and save money. The practice also holds a weekly green agenda meeting, which focuses on everything from inhalers to reusable face masks.

Ellis says her involvement in green matters has completely shifted how she works. "I used to hear about 'patient centred care' and not take much notice, but now I'm more likely to consider the wider determinants of health, such as how the environment impacts on patients."
For example, if she visits an older patient and their home is cold, she'll consider a referral for fuel poverty. Or if a child living near a busy road has asthma, she'll factor in that this could be triggered by pollution.

"Environmental work feels like you're leaving a legacy to create better, fairer care,” Ellis says. "It’s been amazing learning at this early stage in my career how systems come together and work. I'm learning, I'm inspired, and I hope I can inspire others as well." An environmentally sustainable approach to healthcare "feels like a win-win," she believes. "You're saving the practice money, seeing quality improvements, and making staff and patients feel better about their impact on the environment."

Whatever their specialty, she hopes all doctors will recognise the importance of sustainability and take action. "Change is coming. The NHS needs to get to net zero carbon emissions by 2040. Why not be part of how that is achieved?"

\section{How to make the change}

- Get your whole team, including trainees, medical students, nurses, pharmacists, and commissioners, on board

- Prescribing is the number one hot spot for improving a practice's sustainability. You can improve care and reduce impact by looking at medication

- Consider health inequalities, such as people living in fuel poverty, and help advocate for patients

- Start small and build up-find ideas and tools on the green impact for health toolkit 5

- Make your next quality improvement project a sustainable one

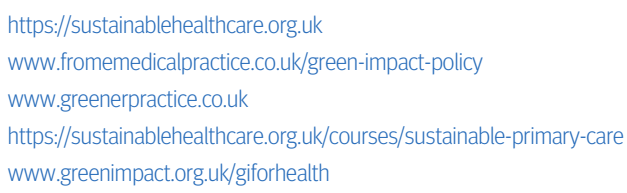

